DOI: $10.18027 / 2224-5057-2021-11-3 s 2-41$

Цитирование: Виценя М.В., Агеев Ф.Т., Гиляров М.Ю., Овчинников А.Г., Орлова Р.В., Полтавская М.Г. Практические рекомендации по коррекции кардиоваскулярной токсичности противоопухолевой лекарственной терапии. Злокачественные опухоли : Практические рекомендации RUSSCO \#3s2, 2021 (том 11). 41

\title{
ПРАКТИЧЕСКИЕ РЕКОМЕНДАЦИИ ПО КОРРЕКЦИИ КАРДИОВАСКУЛЯРНОЙ ТОКСИЧНОСТИ ПРОТИВООПУХОЛЕВОЙ ЛЕКАРСТВЕННОЙ ТЕРАПИИ
}

Коллектив авторов: Виценя М.В., Агеев Ф.Т., Гиляров М.Ю., Овчинников А.Г., Орлова Р.В., Полтавская М.Г.

Ключевые слова: поддерживающая терапия, химиотерапия, кардиотоксичность, дисфункция левого желудочка, сердечная недостаточность, артериальная гипертония, ишемическая болезнь сердца, нарушения ритма сердца

Кардиотоксичность - термин, который включает в себя различные нежелательные явления со стороны сердечно-сосудистой системы, вызванные противоопухолевой терапией. Кардиотоксичность может проявляться как во время лечения, так и после его окончания. Залогом успешной борьбы с проявлениями кардиотоксичности является скоординированная работа онкологов и кардиологов на всех этапах оказания помощи онкологическому больному. Возможные сердечно-сосудистые осложнения противоопухолевой лекарственной терапии солидных опухолей представлены в табл. 1. Всем пациентам до начала потенциально кардиотоксичного противоопухолевого лечения рекомендовано оценить сердечно-сосудистый риск.

Пациенты, которым проводилась или планируется кардиотоксичная химиотерапия и/или лучевая терапия на область грудной клетки или крупных сосудов, относятся к категории высокого и очень высокого сердечно-сосудистого риска (при наличии SCORE > 5\%, СС3, сахарного диабета, систолического АД $\geq 180$ мм рт. ст., семейной гиперлипидемии, СКФ <60 мл/мин).

С целью профилактики сердечно-сосудистых осложнений всем больным независимо от планирующегося лечения рекомендуется:

- здоровый образ жизни, включая здоровое питание, отказ от курения, регулярные физические нагрузки умеренной интенсивности $\geq 150$ мин в неделю;

- $\quad$ выявление и контроль традиционных факторов риска до, в процессе и по окончании лечения с достижением целевых уровней АД < 140/90 мм рт. ст., холестерина липопротеидов низкой плотности < 1,8 ммоль/л при высоком риске, < 1,4 ммоль/л при очень высоком риске, НbA1c < $7 \%$ (> 75 лет $-7,5-8 \%$ ). 
Пациенты, получающие потенциально кардиотоксичную противоопухолевую терапию, независимо от наличия симптомов ССЗ нуждаются в кардиологическом мониторинге с использованием инструментальных и лабораторных методов обследования для своевременного выявления ранних проявлений кардиотоксичности, предотвращения развития клинически значимых сердечно-сосудистых осложнений и связанного с ними прекращения противоопухолевой терапии.

Объем и частота кардиологического мониторинга в процессе и после окончания лечения исходно определяются с учетом сердечно-сосудистого риска пациента и потенциальной кардиовазотоксичности применяемых противоопухолевых средств и могут корректироваться в зависимости от тех или иных ее клинических проявлений.

Консультация кардиолога для оценки необходимости дополнительного лечения и/или интенсивного кардиологического мониторинга показана пациентам:

- с симптомами ССЗ и/или указаниями на ССЗ в анамнезе;

- с очень высоким риском сердечно-сосудистых осложнений;

- с плохо контролируемыми факторами риска (АД, холестерин);

- с существенным повышением сердечных биомаркеров (тропонин, нитрий-уретические пептиды и др.) или значимой патологией при инструментальных исследованиях (ЭКГ, Э×о-КГ).

Таблица 1. Сердечно-сосудистые осложнения противоопухолевой лекарственной терапии солидных опухолей

\begin{tabular}{|c|c|c|c|c|c|c|c|c|c|c|c|c|c|c|c|}
\hline & 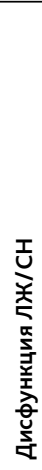 & ᄂ & 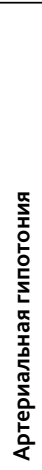 & 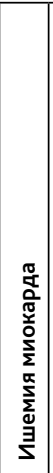 & $\underset{\Sigma}{\Sigma}$ & 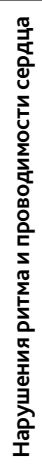 & 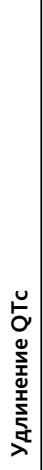 & 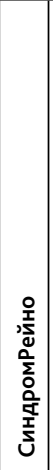 & 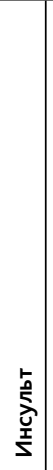 & 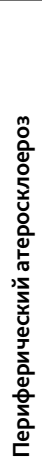 & 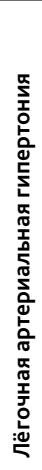 & 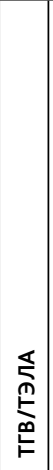 & 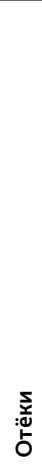 & 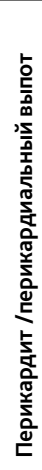 & 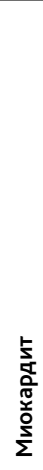 \\
\hline & 1 & 2 & 3 & 4 & 5 & 6 & 7 & 8 & 9 & 10 & 11 & 12 & 13 & 14 & 15 \\
\hline $\begin{array}{l}\text { Антрациклиновые антибиотики } \\
\text { (доксорубицин и др.) }\end{array}$ & $x$ & & & & & $x$ & & & & & & & & & \\
\hline $\begin{array}{l}\text { HER2-таргетная терапия } \\
\text { (трастузумаб, пертузума6 и др.) }\end{array}$ & $x$ & $x$ & & & & & & & & & & & & & \\
\hline $\begin{array}{l}\text { Ингибиторы VEGF (сунитиниб, } \\
\text { сорафениб, пазопатиб, бевацизу- } \\
\text { маб и др.) }\end{array}$ & $x$ & $x$ & & $\mathrm{x}$ & $x$ & $x$ & $x$ & & $x$ & & & $x$ & $\mathrm{x}$ & $x$ & \\
\hline Блеомицин & & & & $x$ & $x$ & & & $x$ & $\mathrm{x}$ & & $x$ & & & & \\
\hline
\end{tabular}




\begin{tabular}{|c|c|c|c|c|c|c|c|c|c|c|c|c|c|c|c|}
\hline & 1 & 2 & 3 & 4 & 5 & 6 & 7 & 8 & 9 & 10 & 11 & 12 & 13 & 14 & 15 \\
\hline $\begin{array}{l}\text { Фторпиримидины (5-фторурацил, } \\
\text { капецитабин, гемцитабин) }\end{array}$ & & & & $x$ & $x$ & $x$ & & $x$ & & & & & & & \\
\hline Паклитаксел & $x$ & $x$ & $x$ & $x$ & $x$ & $x$ & $x$ & & & & & $x$ & $x$ & & \\
\hline Цисплатин & $x$ & $x$ & & $x$ & $x$ & $x$ & & $x$ & $x$ & $x$ & & $x$ & $x$ & & \\
\hline Циклофосфамид & $x$ & & & $x$ & & $x$ & & & & & $x$ & & & $x$ & $x$ \\
\hline Винкристин & & $x$ & $x$ & $x$ & $x$ & $x$ & & $x$ & & & & & & & \\
\hline $\begin{array}{l}\text { Ингибиторы mTOR (эверолимус, } \\
\text { темсиролимус) }\end{array}$ & & $x$ & & $x$ & & & & & & & & $x$ & & & \\
\hline Интерферон-альфа & $x$ & $x$ & $x$ & $x$ & $x$ & $\mathrm{x}$ & & $x$ & $x$ & $x$ & $x$ & $x$ & & & \\
\hline $\begin{array}{l}\text { Ингибиторы контрольных точек } \\
\text { иммунного ответа, блокирующие } \\
\text { PD-1 (ниволубам, пембролизумаб), } \\
\text { CTLA-4 (ипилимумаб), } \\
\text { PD-L1 (авелумаб, атезолизумаб) }\end{array}$ & & & & & $x$ & $x$ & & & & $x$ & & & & $x$ & $x$ \\
\hline $\begin{array}{l}\text { Андрогенная депривационная } \\
\text { терапия (гозерелин, леупролид, } \\
\text { абиратерон) }\end{array}$ & & $x$ & & $x$ & $x$ & & & & & & $x$ & & & & \\
\hline Тамоксифен & & & & & & & & & & & & $x$ & & & \\
\hline $\begin{array}{l}\text { Ингибитор циклин-зависимых } \\
\text { киназ 4/6 (рибоциклиб) }\end{array}$ & & & & & & & $x$ & & & & & & & & \\
\hline $\begin{array}{l}\text { Комбинированная терапия ингиби- } \\
\text { торами RAF и МЕK (дабрафениб+тра- } \\
\text { метиниб, вемурафениб+кобимети- } \\
\text { ниб, энкорафениб+биниметиниб) }\end{array}$ & $x$ & $x$ & & & & & $x$ & & & & & & & & \\
\hline
\end{tabular}

\section{1. ДИСФУНКЦИЯ ЛЕВОГО ЖЕЛУДОЧКА И СЕРДЕЧНАЯ НЕДОСТАТОЧНОСТЬ}

\section{1. Факторы риска}

Систолическая дисфункция Лж/СН наиболее часто связана с применением антрациклиновых антибиотиков и HER2-таргетной терапии (трастузумаб, пертузумаб и др.), а также может развиваться вследствие терапии ингибиторами VEGF (сунитиниб, сорафениб, бевацизумаб) и другими препаратами (табл. 1).

К наиболее значимым факторам, определяющим высокий риск дисфункции лж/СН, относятся:

- высокая суммарная доза антрациклина ( $\geq 250 \mathrm{mr} / \mathrm{m}^{2}$ доксорубицина, $\geq 600 \mathrm{mг} / \mathrm{m}^{2}$ эпирубицина);

- высокая доза лучевой терапии ( $\geq 30$ Гр) на область средостения/левую половину грудной клетки; 
- терапия антрациклинами в низких суммарных дозах в сочетании с лучевой терапией на область средостения/левую половину грудной клетки в низких дозах;

- последовательная терапия антрациклинами и трастузумабом;

- терапия антрациклинами в низких дозах или трастузумабом в сочетании с наличием у пациента двух и более факторов риска ССЗ (артериальной гипертонии, курения, дислипидемии, сахарного диабета, ожирения), сердечно-сосудистых заболеваний (инфаркт миокарда в анамнезе, умеренные и тяжелые клапанные пороки сердца), исходной дисфункцией лж (фракция выброса левого желудочка < $55 \%$ ), возрастом пациента более 60 лет.

\section{2. Диагностика}

\subsection{1. До начала противоопухолевой терапии рекомендовано обследование:}

- сбор жалоб с целью выявления симптомов, типичных для СН (одышка, утомляемость, плохая переносимость нагрузок, отёки нижних конечностей, ортопноэ, сердечная астма), анамнеза (сведения о наличии ИБС, АГ и других ССЗ и их факторов риска, семейный анамнез);

- физикальное обследование с измерением офисного АД;

- ЭхоКГ для оценки ФВлж, общей продольной деформации миокарда (GLS) лж (при доступности метода) и других показателей структурно-функционального состояния сердца;

- МРТ сердца, равновесная изотопная вентрикулография - по показаниям (при недостаточной информативности ЭхоКГ);

- ЭКГ в 12 отведениях с расчётом QTс;

- биохимический анализ крови с определением липидного спектра, глюкозы, креатинина с расчётом клиренса креатинина и/или СКФ, калия, натрия, АСТ, АЛТ, креатинкиназы;

- Сердечные биомаркеры: тропонин I или Т (предпочтительно высокочувствительный), натрийуретические пептиды (BNP, NT-proBNP) - особенно у больных с высоким риском развития дисфункции ЛЖ/СН.

\subsection{2. В процессе терапии}

Рекомендованы опрос и физикальное обследование больных перед каждым циклом XT сцельювыявления симптомов, типичных для СН. Диагностика дисфункции сердца, связанной с противоопухолевой терапией, основана на серийном определении ФВлж. Для мониторинга функции сердца целесообразно использовать тот же метод, который применялся при первичной оценке ФВлж (ЭхоКГ, изотопную вентрикулографию или МРТ). Критерием дисфункции сердца, связанной с противоопухолевой терапией, является снижение ФВлж более, чем на 10 единиц от исходной величины, при абсолютном значении ниже $50 \%$. При доступности рекомендовано определение маркёров субклинического поражения сердца, с высокой точностью предсказывающих последующее снижение ФВлж и развитие $\mathrm{CH}$ :

- GLS; значимым является снижение более чем на 15\% от исходной величины; 
- тропонин I или Т; значимым считается уровень тропонина, превышающий верхнюю границу референсных значений, указанных для каждой конкретной лаборатории.

Частота обследования зависит от режима противоопухолевой терапии и состояния сердечно-сосудистой системы больного. У бессимптомных пациентов с исходно нормальной функцией сердца повторное определение ФВлж, GLS, тропонина I или Т следует проводить по завершении антрациклин-содержащей XT, если доза доксорубицина не превышает 250 мг/м² (или эквивалентной дозы другого антрациклина). При кумулятив-

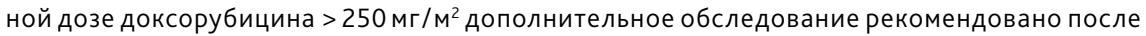
каждого повышения дозы примерно на 100 мг/м² (или примерно 200 мг/м² эпирубицина). Тропониновый тест целесообразно проводить каждые 3-6 недель или перед каждым циклом ХТ в условиях одной и той же лаборатории.

у бессимптомных пациентов с исходно нормальной функцией сердца определение ФВлж, GLS, тропонина I или T (при доступности) рекомендовано проводить каждые 3 месяца в процессе терапии трастузумабом и по ее завершении. Пациентам, исходно имеющим СС3 или нарушение функции сердца, может потребоваться более частый мониторинг.

Алгоритм лечебно-диагностических мероприятий при назначении противоопухолевых препаратов, ассоциирующихся с развитием дисфункции лЖ $\mathrm{CH}$, представлен на рис. 1.

При появлении в процессе противоопухолевой терапии симптомов СН или выявлении бессимптомного снижения ФВлж более чем на 10 единиц от исходной величины и менее $50 \%$ необходимо приостановить лечение, направить пациента на консультацию кардиолога (кардиоонколога) для назначения/коррекции кардиопротективной терапии и повторить обследование через 2-3 недели. Целесообразно подтвердить снижение ФВлж с помощью МРТ, особенно в случаях, когда рассматривается прекращение противоопухолевой терапии из-за развития дисфункции лЖ. Решение о тактике дальнейшего лечения принимается совместно онкологом и кардиологом с учётом имеющихся рисков.

При бессимптомном снижении ФВлж до 40-49\% и принятии решения о возобновлении терапии антрациклинами в связи с отсутствием альтернативного лечения рекомендована оценка ФВлж, сердечных биомаркеров и осмотр кардиологом после каждой последующей дозы антрациклина. При бессимптомном снижении ФВлж до 40-49\% возможно продолжение терапии трастузумабом при более частом мониторинге ФВлж и сердечных биомаркеров. При ФВлж < 40\% терапия антрациклинами и трастузумабом допускается лишь в случае отсутствия альтернативного противоопухолевого лечения. Риск и польза возобновления лечения должны обсуждаться мультидисциплинарной командой и с пациентом.

Снижение показателя GLS и/или повышение уровня тропонина I или Т при нормальном значении ФВлж не является поводом для отмены противоопухолевой терапии, но требует более тщательного дальнейшего мониторинга и консультации кардиолога с целью решения вопроса о назначении кардиопротективной терапии для минимизации риска последующего развития систолической дисфункции ЛЖ/СН. 


\section{3. Профилактика и лечение дисфункции лЖ/СН}

\subsection{1. Профилактика}

Профилактика должна проводиться у всех больных высокого риска её развития. Существуют две основные стратегии профилактики: изменение противоопухолевой терапии с целью снижения её потенциальной кардиотоксичности и использование кардиопротективных препаратов. Профилактика может быть первичной (до начала противоопухолевого лечения) и вторичной - по факту появления маркёров субклинического поражения сердца (повышение уровня биомаркеров повреждения миокарда, снижение GLS при отсутствии симптомов сердечной недостаточности).

Возможные меры профилактики включают:

- ограничение кумулятивной дозы антрациклинов в рекомендованных пределах (доксорубицин < $360 \mathrm{mг} / \mathrm{m}^{2}$, даунорубицин < $800 \mathrm{mг} / \mathrm{m}^{2}$, эпирубицин $<720 \mathrm{mr} / \mathrm{m}^{2}$,

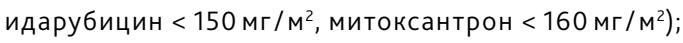

- использование менее кардиотоксичных режимов противоопухолевой терапии (без антрациклинов), если имеются доказательства не меньшей их эффективности;

- использование липосомальной формы доксорубицина (при раке яичников, ВИчассоциированной саркоме Капоши, при неэффективности по крайней мере одной линии предшествующей терапии, при метастатическом раке молочной железы);

- отказ от одновременного назначения антрациклинов и трастузумаба;

- коррекция модифицируемых факторов риска и лечение имеющихся у больного ССЗ согласно общепринятым рекомендациям с использованием ингибиторов ангиотензин-превращающего фермента (эналаприл, рамиприл, периндоприл и др.)/блокаторов рецепторов ангиотензина II (кандесартан, телмисартан, валсартан и др.) и/или бетаадреноблокаторов (предпочтительно карведилол, небиволол); статинов (аторвастатин и др.) у пациентов с дислипидемией;

- применение эналаприла в качестве средства вторичной профилактики при повышении уровня тропонина на фоне терапии антрациклинами;

- дексразоксан (при его доступности) при метастатическом РМЖ, если кумулятив-

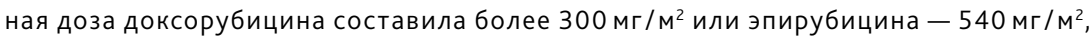
в случае целесообразности продолжения терапии антрациклинами, а также при исходном поражении сердца (наряду с проводимой кардиологической терапией) больным, которым показана терапия антрациклинами, независимо от типа онкологического заболевания;

- регулярные аэробные физические нагрузки (не менее 150 мин в нед.) при терапии антрациклинами.

\subsection{2. Лечение}

При выявлении дисфункции ЛЖ, соответствующей критериям кардиотоксичности, вопрос о тактике дальнейшего ведения больного решается в зависимости от степени снижения и значения ФВлж, наличия симптомов СН и времени выявления (на фоне про- 
ведения или после окончания противоопухолевой терапии). При развитии дисфункции лЖ/СН на фоне лечения противоопухолевую терапию следует приостановить. Пациентам с дисфункцией лж, даже при отсутствии клинических проявлений, необходимо как можно раньше начинать стандартную терапию $\mathrm{CH}$, предусмотренную клиническими рекомендациями для общей популяции. Терапия включает диету (ограничение потребления соли, жидкости), режим физической активности с учётом исходной толерантности к физическим нагрузкам, медикаментозные, электрофизиологические, хирургические, механические методы лечения, а также психологическую реабилитацию. От своевременности назначенного лечения зависит вероятность восстановления (частичного или полного) функции ЛЖ. Для назначения оптимальной терапии и последующего контроля её эффективности и безопасности необходима консультация кардиолога.

\section{4. Наблюдение после окончания противоопухолевой терапии, связанной с риском развития дисфункции левого желудочка и сердечной недостаточности}

Частота обследования после завершения антрациклин-содержащей ХТ зависит от клинической ситуации и определяется индивидуально.

Бессимптомным больным с нормальной сократимостью сердца после лечения кардиотоксичными препаратами показано обследование с целью исключения дисфункции лж спустя 6-12 месяцев, в последующем - раз в 2 года.

Больным, у которых в процессе лечения наблюдались признаки субклинической кардиотоксичности или СН, может потребоваться более частое обследование и наблюдение у кардиолога. 


\section{5. Алгоритмы ведения больных, получающих противоопухолевую терапию, ассоциирующуюся с развитием дисфункции левого желудочка и сердечной недостаточности}

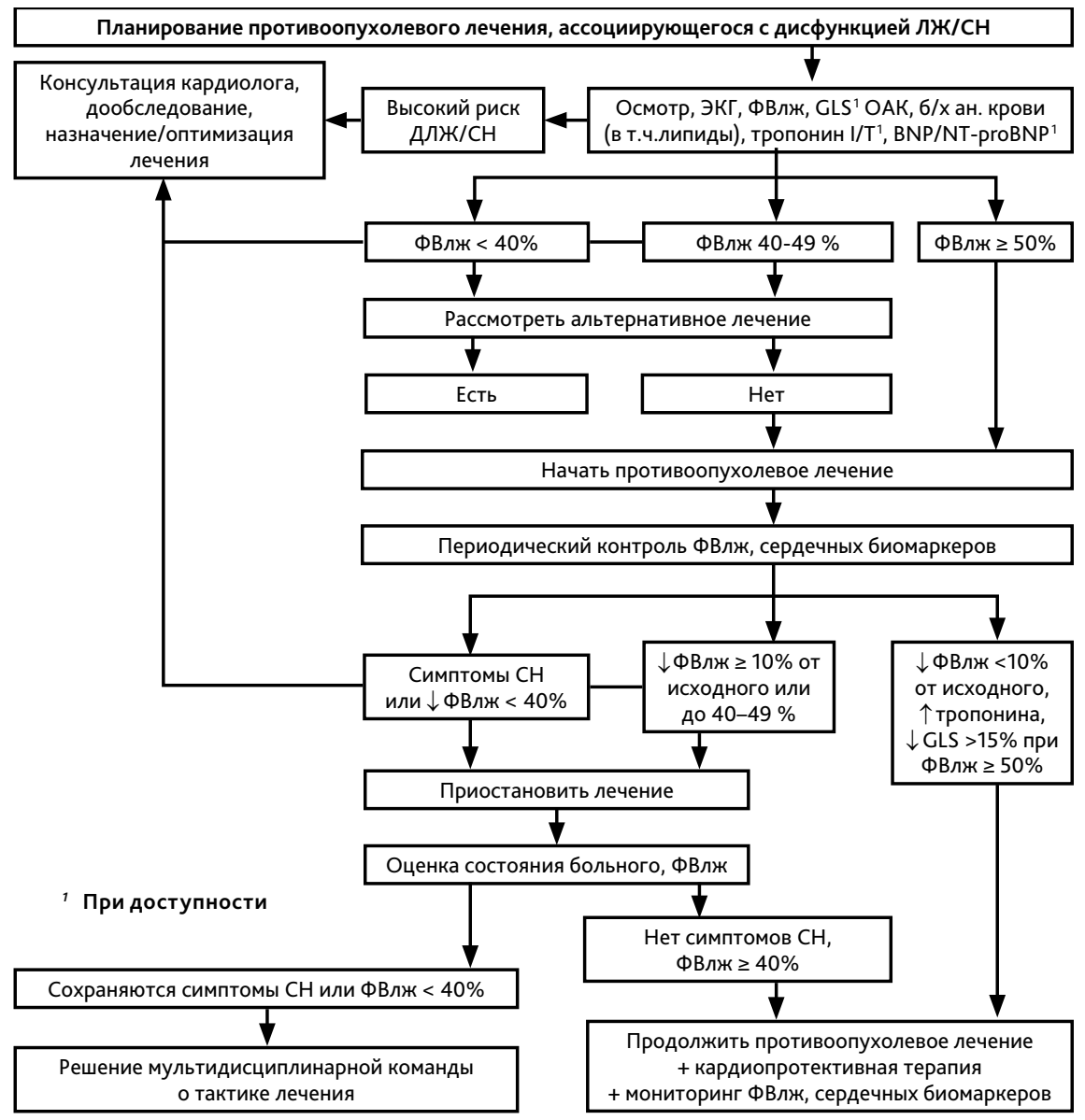

Рисунок 1. Рекомендуемый алгоритм лечебно-диагностических мероприятий при назначении противоопухолевых препаратов, ассоциирующихся с развитием дисфункции левого желудочка и сердечной недостаточности. 


\section{2. ИШЕМИЧЕСКАЯ БОЛЕЗНЬ СЕРДЦА}

\section{1. Классификация и факторы риска}

Ишемические осложнения (стенокардия напряжения и покоя, безболевая ишемия миокарда, ИМ и индуцированные ишемией нарушения ритма сердца) наиболее часто связаны с применением фторпиримидинов (5-фторурацил, капецитабин, гемцитабин), препаратов платины (цисплатин), таксанов (паклитаксел), анти VEGF терапии (бевацизумаб, сорафениб, сунитиниб, и др., табл. 1). Препараты различаются по патогенетическим механизмам сосудистой токсичности (вазоспазм, артериальный тромбоз, ускорение атерогенеза) и продолжительности неблагоприятных эффектов (преходящий и долгосрочный типы токсичности), что влияет на выбор тактики ведения больных в процессе и после завершения противоопухолевой терапии.

\section{Факторы риска развития ишемических осложнений}

- ИБС (стенокардия, безболевая ишемия, ИМ, коронарная реваскуляризация в анамнезе);

- $\mathrm{Ar}$;

- сахарный диабет;

- дислипидемия;

- курение;

- ожирение;

- малоподвижный образ жизни;

- семейный анамнез раннего развития ИБС или инсульта (у мужчин до 55 лет, у женщин - до 60 лет);

- нарушения мозгового кровообращения в анамнезе;

- венозные и артериальные тромбозы, тромбоэмболия в анамнезе;

- синдром Рейно в анамнезе;

- сопутствующая или предшествующая лт;

- пожилой возраст.

\section{2. Диагностика}

\subsection{1. До начала терапии:}

- сбор жалоб (выявление клинических симптомов стенокардии) (табл. 3), анамнеза (сведения о наличии ИБС, АГ и других ССЗ и их факторов риска);

- физикальное обследование;

- ЭКГ в 12 отведениях;

- ЭхоКГ; 
- нагрузочные пробы (велоэргометрия, тредмил-тест, стресс-эхокардиография, однофотонная эмиссионная компьютерная томография с нагрузкой), холтеровское мониторирование ЭКГ для верификации ишемии - по показаниям";

- коронароангиография, МСКТ коронарных артерий - по показаниям";

- клинический анализ крови;

- биохимический анализ крови с определением общего холестерина, холестерина липопротеидов низкой плотности, холестерина липопротеидов высокой плотности, триглицеридов, глюкозы, трансаминаз, креатинкиназы, креатинина и расчётом клиренса креатинина и/или СКФ, калия, натрия.

\subsection{2. В процессе терапии:}

- опрос больного с целью выявления клинических симптомов стенокардии напряжения или покоя (и их эквивалентов);

- ЭКГ в 12 отведениях перед каждым циклом терпаии, ассоциирующейся с ишемическими осложнениями (в перую очередь - фторпиримидинами), а также при появлении клинических симптомов стенокардии для выявления признаков ишемии миокарда;

- нагрузочные пробы, холтеровское мониторирование ЭКГ для верификации ишемиипо показаниям²;

- коронароангиография, МСКТ коронарных артерий - по показаниям².

Таблица 2. Клиническая классификация болей в грудной клетке

\begin{tabular}{|l|l|}
\hline Типичная стенокардия & $\begin{array}{l}\text { Соответствует всем трём следующим признакам: } \\
\text { боль за грудиной, возможно с иррадиацией в левую руку, спину, челюсть } \\
\text { (одышка как эквивалент) длительностью до 5 мин.; } \\
\text { - провокация физической или эмоциональной нагрузкой; } \\
\text { - купирование в покое и/или после приёма нитроглицерина }\end{array}$ \\
\hline Атипичная стенокардия & При наличии 2 из 3 признаков \\
\hline $\begin{array}{l}\text { Неангинозная боль } \\
\text { в грудной клетке }\end{array}$ & Соответствует одному из признаков или не соответствует им вообще \\
\hline
\end{tabular}

\section{3. Профилактика и лечение}

До начала терапии, ассоциирующейся с ишемическими осложнениями, всем больным должны быть даны рекомендации по изменению образа жизни, необходима коррекция

1 При наличии болей ангинозного характера, анамнестических указаний на наличие ИБС; рекомендована консультация кардиолога для определения оптимальной тактики дальнейшего обследования и лечения.

2 При появлении на фоне терапии болей ангинозного характера, усугублении ранее имевшихся симптомов стенокардии или выявлении ЭКГ-признаков безболевой ишемии миокарда необходимо приостановить терапию, рекомендована консультация кардиолога для определения оптимальной тактики дальнейшего обследования илечения. 
модифицируемых факторов риска ССЗ и оптимизация терапии имеющихся СС3 согласно общепринятым рекомендациям. У больных ИБС при возможности следует избегать продолжительной и высокодозной терапии фторпиримидинами и другими противоопухолевыми препаратами, ассоциирующимися с риском ишемических осложнений. При отсутствии альтернативы терапию проводить в условиях частого мониторинга симптомов ИБС и ЭКГ.

При развитии ишемии миокарда рекомендовано приостановить терапию, назначить нитраты (нитроглицерин сублингвально или изосорбида динитрат в ингаляциях) при тщательном мониторинге. Если пациент находится вне медицинского учреждения, ему следует рекомендовать немедленно вызвать Скорую медицинскую помощь.

При планировании дальнейшего лечения препаратом, вызвавшим ишемию миокарда, или сходными препаратами необходима консультация кардиолога, тщательное обследование и коррекция терапии. В случае документированного вазоспазма (элевация сегмента ST на ЭКГ) возобновление терапии возможно только при отсутствии альтернативы, на фоне назначения профилактической терапии и продолжительного ЭКГ мониторинга в день введения препарата. В случае возобновления терапии 5-фторурацилом предпочтительны схемы лечения, предполагающие болюсное, а не продолжительное инфузионное введение препарата. Может быть предложен 3-дневный курс нитратов или антагонистов кальция: за сутки до, во время и сутки после введения препарата. Следует учитывать, что у большого числа пациентов такая терапия не предотвращает появления ишемии миокарда

При наличии симптомов и признаков, позволяющих подозревать острый коронарный синдром - ИМ (интенсивная боль за грудиной продолжительностью более 20 мин, сопровождающаяся слабостью, одышкой, кашлем, сердцебиением, обмороком, характерными изменениями ЭКГ), нестабильную стенокардию (впервые возникшая, прогрессирующая стенокардия), показана экстренная госпитализация в специализированное кардиологическое отделение с блоком интенсивной терапии для проведения комплекса диагностических и лечебных мероприятий. До приезда бригады скорой медицинской помощи показан приём ацетилсалициловой кислоты 500 мг (разжевать), при продолжающемся болевом синдроме - нитроглицерин сублингвально. Следует избегать возобновления противоопухолевой терапии у больных с развившимся на её фоне ИМ. У пациентов с гемодинамически значимым поражением коронарных артерий попытка возобновления прежней противоопухолевой терапии может быть рассмотрена после реваскуляризации миокарда при отсутствии альтернативного лечения после тщательного сопоставления предполагаемой пользы и риска (рис. 2) . 
Общеклиническое обследование перед началом терапии:

сбор жалоб, анамнеза, физикальное обследование, ЭКГ в 12 отведениях, ЭхоКГ, общий и биохимический анализы крови (липидный спектр, глюкоза, трансаминазы, креатинин и др.)

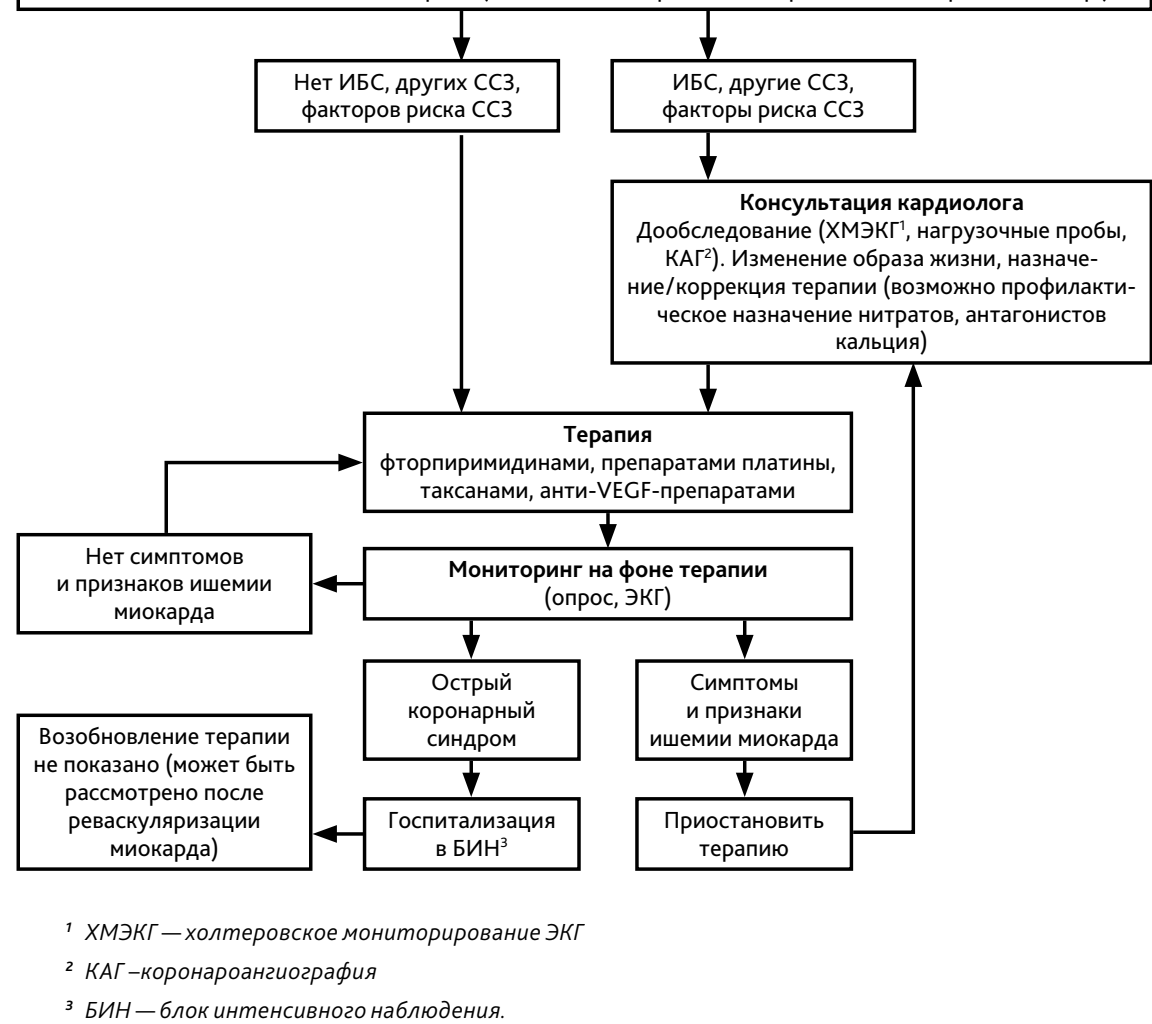

Рисунок 2. Рекомендуемый алгоритм лечебно-диагностических мероприятий при назначении противоопухолевых препаратов, ассоциирующихся с развитием ИБС.

\section{4. Наблюдение после окончания противоопухолевой терапии, связанной с риском развития ИБС}

У пациентов, пролеченных препаратами с долгосрочной сосудистой токсичностью (препараты платины, блеомицин, интерферон альфа), пожизненно повышен риск заболевания ИБС. Больным необходимо дать рекомендации по изменению образа жизни и коррекции модифицируемых факторов риска СС3 (повышение физической активности, отказ от курения, здоровое питание, контроль АД, уровня глюкозы и липидов крови). Рекомендуется ежегодное кардиологическое обследование, включающее: 
- опрос для выявления кардиальных симптомов;

- физикальное исследование;

- ЭКГ;

- нагрузочные тесты (по показаниям);

- исследование лодыжечно-плечевого индекса;

- ультразвуковое исследование магистральных артерий головы - раз в 2 года.

\section{3. АРТЕРИАЛЬНАЯ ГИПЕРТОНИЯ}

Артериальная гипертония - наиболее распространённая коморбидная сердечнососудистая патология у пациентов со злокачественными новообразованиями. Она может быть обусловлена как самим онкологическим заболеванием (например, рак почки), так и противоопухолевой терапией. Возникновение или дестабилизация ранее контролируемой АГ наиболее часто (у 11-45\% больных) наблюдается при применении ингибиторов VEGF (сунитиниб, сорафениб, бева- цизумаб и др.). К АГ могут предрасполагать и другие виды противоопухолевой и сопутствующей терапии: алкилирующие средства (цисплатин, циклофосфамид), стероидные гормоны, НПВС, эритропоэтин.

\section{1. Факторы риска повышения артериального давления на фоне анти-VEGF терапии}

- АД $\geq 140 / 90$ мм рт. ст. до начала терапии;

- сахарный диабет;

- ССЗ (ишемический инсульт, транзиторная ишемическая атака, кровоизлияние в мозг в анамнезе; ИМ, стенокардия, коронарная реваскуляризация; $\mathrm{CH}$; болезни периферических артерий);

- субклиническое поражение органов-мишеней (гипертрофия Лж; хроническая болезнь почек со снижением СКФ < 60 мл/мин/1,73 м², микроальбуминурия; утолщение комплекса интима-медиа сонных артерий >0,9 мм, наличие атеросклеротических бляшек);

- факторы риска ССЗ (курение, дислипидемия, ожирение, малоподвижный образ жизни).

\section{2. Диагностика}

\subsection{1. До начала терапии рекомендовано обследование:}

- сбор анамнеза (сведения о наличии АГ и других ССЗ, семейный анамнез);

- физикальное обследование с измерением офисного АД;

- внеофисное измерение АД (суточное мониторирование АД, самоконтроль АД) - по показаниям, особенно при подозрении на «гипертонию белого халата»;

- ЭКГ для выявления гипертрофии лЖ, аритмий, сопутствующих болезней сердца;

- ЭхоКГ для определения структурно-функционального состояния сердца;

- биохимический анализ крови с определением креатинина и расчётом клиренса креатинина и/или СКФ, калия, натрия, липидного спектра, глюкозы; 
- общий анализ мочи;

- тест на микроальбуминурию (при доступности);

- УзИ почек, ультразвуковое дуплексное сканирование почечных артерий-по показаниям.

\subsection{2. В процессе анти-VEGF терапии}

Рекомендован еженедельный мониторинг АД на первом цикле терапии и затем, как минимум, каждые 2-3 недели во время лечения. После окончания первого цикла терапии, если АД остаётся на целевом уровне, мониторинг может быть ограничен рутинным офисным измерением или самоконтролем АД в домашних условиях. Из-за возможных нефротоксических эффектов при доступности целесообразно проводить тест на микроальбуминурию в динамике.

\section{3. Профилактика и лечение}

До начала терапии необходима коррекция модифицируемых факторов риска СС3 и оптимизация терапии имеющихся ССЗ. Лечение АГ проводится согласно общепринятым рекомендациям, однако целесообразно раннее назначение фармакологической терапии. Цель лечения - снижение краткосрочных рисков, связанных с опосредованными АГ заболеваниями, наряду с сохранением эффективной противоопухолевой терапии. Задача - достижение и поддержание целевого уровня АД (менее 140/90 мм рт. ст. и ниже при наличии протеинурии). Рекомендовано изменение образа жизни (изменение режима питания, ограничение употребления поваренной соли, увеличение физической активности, нормализация веса, отказ от курения) и раннее фармакологическое лечение, для назначения или коррекции которого целесообразна консультация кардиолога или терапевта.

В качестве препаратов I линии для лечения АГ, индуцированной анти-VEGF терапией, предлагается использовать ингибиторы ангиотензин-превращающего фермента (эналаприл, лизиноприл, рамиприл, периндоприл, фозиноприл и др.), блокаторы рецепторов ангиотензина II (валсартан, лозартан, телмисартан и др.) и дигидропиридиновые антагонисты кальция (амлодипин, фелодипин).

У пациентов с ИБС или риском развития дисфункции лж/СН помимо ингибиторов ангиотензин-превращающего фермента и блокаторов рецепторов ангиотензина II рекомендовано использование бета-адреноблокаторов (предпочтительно небиволол, карведилол).

Диуретики не следует использовать в качестве препаратов I линии для лечения АГ, индуцированной анти-VEGF терапией, в связи с повышением риска электролитных нарушений и удлинения интервала QTC. Не рекомендовано совместное назначение недигидропиридиновых антагонистов кальция дилтиазема и верапамила с анти-VEGF препаратами в связи с возможным межлекарственным взаимодействием.

Вопрос об уменьшении дозы или приостановлении противоопухолевой терапии может рассматриваться только при неконтролируемой или осложнённой АГ. При достижении контроля АД терапия должна быть возобновлена при тщательном мониторинге (рис. 3). 


\section{Общеклиническое обследование перед началом терапии:}

анамнез, осмотр с измерением АД, общий и биохимический анализы крови, общий анализ мочи, ЭхоКГ, ЭКГ

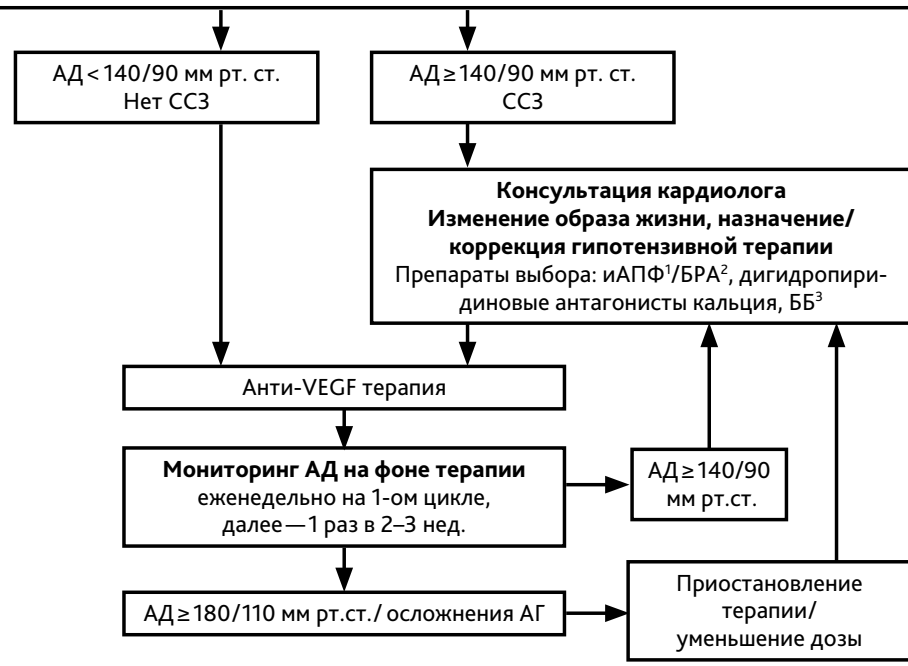

1 иАПФ-ингибиторы ангиотензин-превращающего фермента

2 БРА - блокаторы рецепторов ангиотензина II

${ }^{3}$ ББ-бета-адреноблокаторы.

Рисунок 3. Рекомендуемый алгоритм лечебно-диагностических мероприятий на фоне антиVEGF-терапии.

\section{4. НАРУШЕНИЯ РИТМА И ПРОВОДИМОСТИ СЕРДЦА}

Пациенты с онкологическими заболеваниями могут страдать различными нарушениями ритма и проводимости сердца (тахи- и брадиаритмиями), которые могут быть связаны с сопутствующей раку патологией, прямым действием опухоли или токсическим эффектом противоопухолевой терапии. Удлинение интервала QT и сопряжённое с ним жизнеугрожающее нарушение ритма в виде полиморфной желудочковой тахикардии типа «пируэт» могут быть вызваны назначением различных химиотерапевтических средств (табл. 1), наиболее часто - триоксидом мышьяка, таргетными препаратами (сорафениб, сунитиниб, лапатиниб), ингибиторами CDK 4/6 (рибоциклиб), а также электролитными расстройствами, сопутствующей медикаментозной терапией и другими предрасполагающими факторами (табл. 4). Из наджелудочковых тахиаритмий особого внимания заслуживает фибрилляция предсердий, которая сопряжена с высоким риском инсульта и системных тромбоэмболических осложнений, что требует рассмотрения вопроса о назначении антикоагулянтной терапии. 


\section{1. Факторы риска удлинения интервала QT}

Существуют 2 типа факторов риска, представленные в табл. 3.

Таблица 3. Факторы, предрасполагающие к удлинению интервала QT

\begin{tabular}{|c|c|}
\hline Модифицируемые & Немодифицируемые \\
\hline 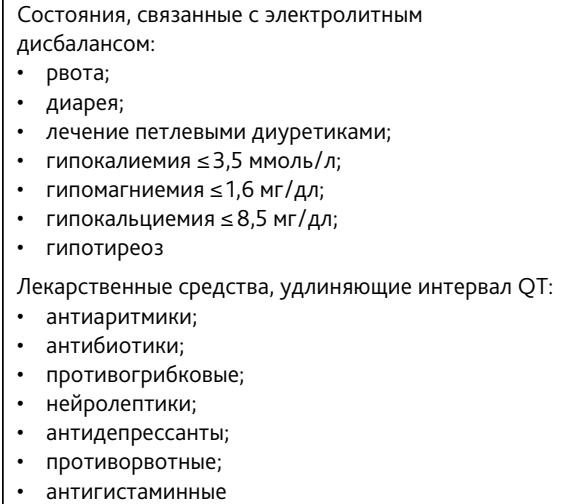 & 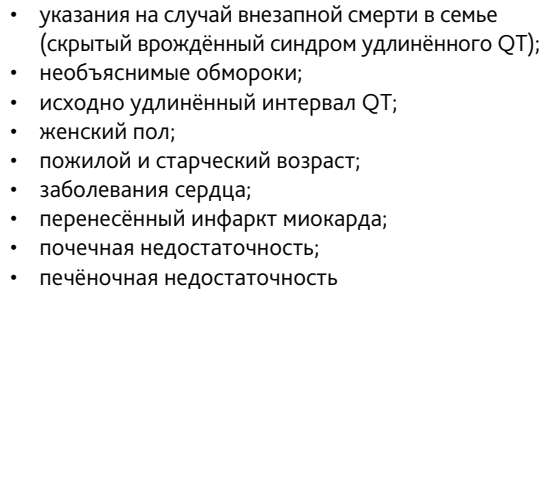 \\
\hline
\end{tabular}

\section{2. Диагностика}

\subsection{1. До начала лечения}

- Сбор жалоб (перебои в работе сердца, неритмичное сердцебиение, синкопальные состояния);

- анамнеза (сведения о наличии нарушений ритма сердца и других СС3);

- физикальное обследование;

- ЭКГ в 12 отведениях с определением корригированного интервала QT (QTc) и оценкой факторов, потенциально влияющих на его величину. Величина QTс определяется автоматически (на современных электрокардиографах) или по формуле Базетта (QTc=QT/ $\sqrt{R R}$, сек при ЧСC 60-100 ударов/мин.), по формуле Фредерика (QTc=QT/3RR, сек при чСС < 60 и > 100 ударов/мин.). Нормальное значение QTс для мужчин менее 430 мс, для женщин - менее 450 мс;

- холтеровское мониторирование ЭКГ;

- ЭхоКГ;

- биохимический анализ крови с определением калия, натрия, магния;

- определение тиреоидных гормонов.

\subsection{2. В процессе лечения}

- Опрос больного с целью выяснения клинических симптомов нарушений ритма сердца;

- ЭКГ в 12 отведениях перед каждым циклом терапии или чаще при необходимости. 
В процессе лечения препаратами, способными удлинять интервал QT, следует регистрировать ЭКГ в 12 отведениях с определением QTc: на 7-15 день после начала лечения или изменения дозы, далее - ежемесячно в течение первых 3 мес. и затем - периодически при продолжении лечения. Еженедельная регистрация ЭКГ рекомендована пациентам, имеющим патологию сердца, удлинённый интервал QT в анамнезе, электролитные расстройства, брадикардию, гипотиреоз, а также получающим сопутствующие препараты, удлиняющие интервал QT.

При увеличении длительности QTс> 500 мс или более, чем на 60 мс от исходного значения следует временно прекратить противоопухолевое лечение и устранить возможные предрасполагающие факторы (электролитные расстройства, брадикардию) (рис. 4). Лечение может быть возобновлено в уменьшенной дозе после нормализации величины QTс. При отсутствии альтернативного эффективного лечения для данной конкретной опухоли следует продолжить лечение препаратом, удлинившим QTс, осуществляя более частый мониторинг ЭКГ, вплоть до постоянного с помощью прикроватного или носимого телемонитора.

\section{3. Лечение}

Лечение нарушений ритма и проводимости сердца проводится согласно общепринятым рекомендациям, однако должно быть индивидуализировано. Решение о назначении антиаритмических препаратов или об использовании имплантируемых устройств должно приниматься на основании ожидаемой продолжительности жизни с точки зрения течения онкологического заболевания, риска смерти от сердечной патологии, качества жизни и риска развития осложнений.

\subsection{1. В случае возникновения пробежек желудочковой тахикардии типа «пируэт»}

Следует назначить внутривенную инфузию 10 мл 25\% раствора магния сульфата, при тенденции к брадикардии возможно использование учащающей трансвенозной кардиостимуляции или внутривенно инфузии допамина или добутамина. В случае развития устойчивого пароксизма желудочковой тахикардии «пируэт» проводят электрическую кардиоверсию.

\subsection{2. Фибрилляция предсердий и трепетание предсердий}

При возникновении фибрилляции или трепетания предсердий рекомендована консультация кардиолога для назначения или коррекции терапии и последующего контроля её эффективности и безопасности. Решение о выборе тактики контроля ритма или частоты сердечных сокращений должно основываться на выраженности симптомов аритмии и выборе пациента.

Для оценки риска развития инсульта и тромбоэмболических осложнений используется шкала CHA2DS2-VASc. Наличие $\geq 2$ баллов является показанием к назначению антикоагулянтов. При наличии 1 балла у мужчин или 1 балла у женщин (если этот фактор не женский пол) возможно назначение антикоагулянтов, если нет высокого риска кровотечений. Последний определяется по наличию факторов риска (модифицируемых и немодифицируемых) на основании шкал риска кровотечений (HAS-BLED, HEMORR2HAGES, ATRIA, ORBIT, ABC). Следует 
учесть, что, с одной стороны, рак является протромбогенным состоянием, с другой - он может увеличивать риск кровотечений (распад опухоли, аррозия сосуда, снижение числа тромбоцитов и т. п.). В настоящее время в качестве антикоагулянтов могут рассматриваться низкомолекулярные гепарины (в краткосрочной и среднесрочной перспективе), варфарин или новые оральные антикоагулянты (дабигатран, апиксабан и ривароксабан) при уровне тромбоцитов не менее 50,0 ×10\% / .

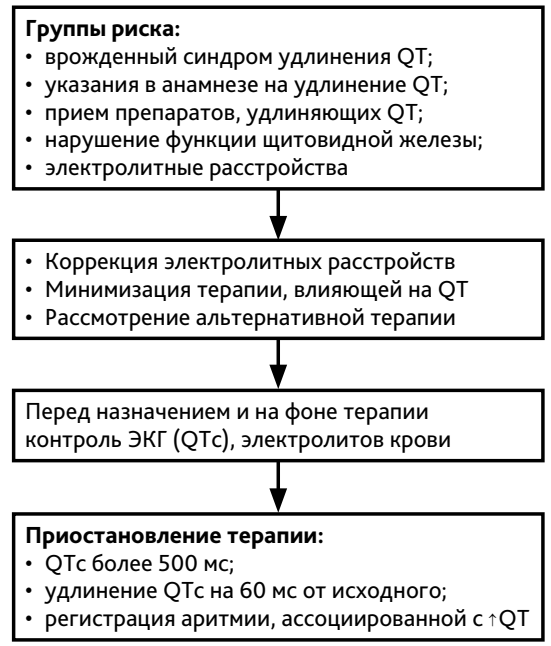

Рисунок 4. Рекомендуемый алгоритм лечебно-диагностических мероприятий при назначении противоопухолевых препаратов, удлиняющих интервал QT.

\section{5. МИОКАРДИТ, ИНДУЦИРОВАННЫЙ ИНГИБИТОРАМИ КОНТРОЛЬНЫХ ТОЧЕК ИММУННОГО ОТВЕТА (ИКТ)}

Терапия ИКТ может сопровождаться целым рядом иммуно-опосредованных побочных эффектов, включая миокардит. Клинические проявления варьируют от бессимптомного повышения сердечных тропонинов до фульминантного миокардита с быстрым развитием кардиогенного шока, тяжелыми нарушениями ритма и проводимости (желудочковые тахикардии, АВ блокады 2 и 3 степени). Хотя частота тяжелого миокардита невелика (до 1,1\%), летальность составляет от 25 до $50 \%$. Миокардит может манифестировать по типу острой или хронической сердечной недостаточности, а также «острого коронарного синдрома», что требует исключения коронарной патологии. Возможен выпот в перикарде, который необходимо дифференцировать с опухолевым перикардитом, в первую очередь при раке легкого. Кардиотоксичность нередко сочетается с некардиальными иммунными осложнениями, такими как миастения и миозит. В типичных случаях кардиотоксичность развивается 
в первые 1-2 месяца терапии ИКТ, однако возможны как ранний дебют после первой же инфузии, так и поздний - через год и более на фоне длительной терапии.

\section{1. Факторы риска}

Факторы риска кардиотоксичности ИКТ неизвестны. Более внимательный мониторинг рекомендуется при назначении комбинированной иммунотерапии.

\section{2. Диагностика}

\subsection{1. До начала терапии}

- сбор жалоб и анамнеза (сведения о наличии ССЗ и их факторов риска);

- физикальное обследование;

- ЭКГ в 12 отведениях;

- ЭхоКГ;

- Кардиомаркеры (тропонин, BNP или NT-proBNP).

\subsection{2. В процессе терапии}

- Опрос больного с целью выявления симптомов, позволяющих заподозрить миокардит: появление болей в груди, одышки, ортопноэ, ночных приступов удушья, слабости, обмороков, жалоб на перебои в сердце и сердцебиения;

- При отсутствии симптомов кардиотоксичности в течение первого месяца терапии еженедельно рекомендуется:

- ЭКГ в 12 отведениях;

- анализ на сердечный тропонин (в первую очередь у пациентов, получающих комбинацию ИКТ.

- При появлении симптомов, подозрительных на миокардит, и/или изменений на ЭКГ, повышении тропонина:

- консультация кардиолога (желательно кардиоонколога);

- расширенное обследование: ЭКГ, Тропонины, BNP или NT-proBNP, C-реактивный белок, вирусологическое исследование, ЭхоКГ с оценкой GLS (при возможности), МРТ сердца, эндомиокардиальная биопсия, коронароангиография (объем обследования определяется кардиологом).

Диагноз миокардита может быть подтвержден на основании МРТ сердца и/или биопсии миокарда. Учитывая вероятность фульминантного течения, обследование должно быть проведено максимально быстро.

\section{3. Профилактика и лечение}

Меры профилактики кардиотоксичности ИКТ не разработаны.

При подозрении или подтвержденном диагнозе миокардита противоопухолевую терапию следует остановить, госпитализировать пациента в кардиологическое отделение или отде- 
ление интенсивной терапии (в зависимости от клинических проявлений) и незамедлительно (желательно в первые 24 часа) начать лечение высокими дозами кортикостероидов (метилпреднизолон в/в 1000 мг в сутки с переходом на таблетированный преднизолон 1 мг/кг/сутки). При отсутствии быстрого эффекта возможно добавление других иммуносупрессивных препаратов: антитимоцитарного иммуноглобулина, инфликсимаба (кроме больных с СН), микофенолата мофетила или абатацепта. Терапию продолжать до исчезновения симптомов, нормализации уровня тропонина, систолической функции лж и проводимости сердца.

Лечение $\mathrm{CH} /$ дисфункции левого желудочка, нарушений ритма и проводимости проводить на основании соответствующих клинических рекомендаций.

\section{4. Алгоритм ведения больных, получающих терапию ИкТ}

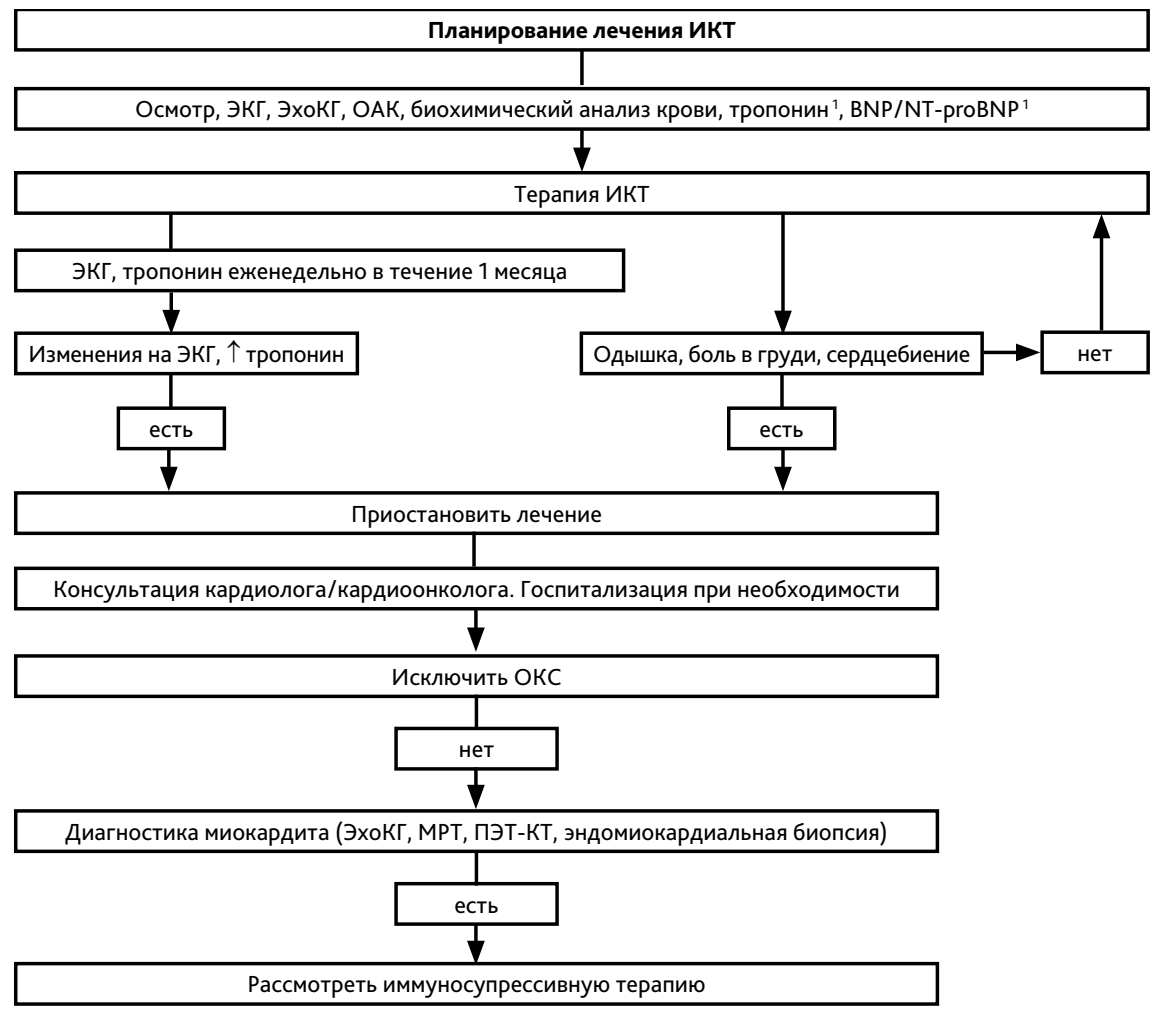

* При доступности

Рисунок 5. Рекомендуемый алгоритм лечебно-диагностических мероприятий при назначении ИКТ. 


\section{Возможность возобновления терапии ИКТ}

Решение о возобновлении терапии ИКТ после лечения по поводу кардиотоксичности при отсутствии альтернативы принимается строго индивидуально мультидисциплинарной командой на основании оценки риска и ожидаемой пользы с учетом стадии онкологического процесса, ответа на предшествующее лечение, тяжести кардиотоксичности и ее ответа на терапию, предпочтений пациента. Возобновление терапии ИкТ крайне нежелательно после подтвержденного миокардита, тяжелых нарушениях ритма и проводимости сердца. Если принято решение о возобновлении терапии, следует выбрать монотерапию ингибиторами программируемой гибели клеток 1 типа (анти-PD-1) с частым последующим кардиомониторингом.

Если миокардит исключен, а повышение тропонина было обусловлено инфарктом миокарда, болезнью Такоцубо, фибрилляцией предсердий и другими причинами, возможно возобновление терапии ИКТ после стабилизации состояния пациента при условии частого мониторинга. При ОКС решение о возобновлении терапии должно приниматься не ранее, чем через месяц с учетом результатов повторного тестирования на кардиомаркеры. 